\title{
Agricultural land-use change and ash (Fraxinus excelsior L.) colonization in Pyrenean landscapes: an interdisciplinary case study
}

\author{
A. Mottet • M. P. Julien • G. Balent • A. Gibon
}

Received: 31 October 2004 /Revised: 1 February 2006 / Accepted: 1 May 2006 /Published online: 9 January 2007

(C) Springer Science + Business Media B.V. 2007

\begin{abstract}
Changes in agricultural land use are responsible for significant modifications in mountain landscapes. This study is part of an interdisciplinary research on the processes and consequences of spontaneous afforestation of Pyrenean landscapes by ash, and the possibilities for its management. We address the relationships between vegetation dynamics and land-use change from the combination of an agricultural study of change in farm management and an ecological study of grassland colonization by ash. In the framework of a village case study, we characterized parcels management and land-use histories, and analyzed the dynamics of the composition of grassland vegetation communities. From a joint analysis of the results obtained in each discipline, we discuss the limitations and complementarities of the two approaches for the interdisciplinary assessment of the afforestation process.
\end{abstract}

Keywords land-use change $\cdot$ farmer's management practices · grazing intensity $\cdot$ reference model . biomass removal $\cdot$ biomass production

\section{Introduction}

Agricultural abandonment is an important factor in landscape change in European mountains [9, 20, 25]. Traditional

\footnotetext{
A. Mottet $\cdot$ M. P. Julien · G. Balent $\cdot$ A. Gibon UMR 1201 DYNAFOR, INRA INPT/ENSAT,

52627, 31326 Castanet-Tolosan Cedex, France

A. Mottet $(\bowtie)$

GEB-Institut de l'Elevage, 149 rue de Bercy,

75595 Paris Cedex 12, France

e-mail: anne.mottet@inst-elevage.asso.fr
}

agro-pastoral systems had evolved slowly over a long period, a process that shaped typical mountain cultural landscapes $[4,11,25]$. However, since the middle of the 20th century, the modernization of farming has led to considerable changes in agricultural systems, resulting in the abandonment of part of the agricultural land and also of some traditional grassland management practices $[2, \underline{8}, 10$, 21]. Spontaneous afforestation with native tree species is a widespread consequence of such changes. In France, for example, this has resulted in a gain of 97,000 ha year ${ }^{-1}$ over the period 1992-2002, which accounts for about $87 \%$ of the annual forest increase in the country [22]. Control of the afforestation process and its impacts on landscape functions is regarded as a difficult challenge for land managers and land policymakers [12].

The work reported in this paper was carried out as part of an interdisciplinary research on the processes and consequences of colonization of Pyrenean landscapes by ash (Fraxinus excelsior L.). Ash used to be an important multipurpose tree species in traditional Pyrenean agropastoral systems, where it grew in hedges or as isolated trees. The objectives of the study are to improve our understanding of the farmland afforestation process and to provide local land managers and development policymakers with references and tools for supporting sustainable landscape development.

This work addresses the relationships between land-use change and landscape colonization by ash based on an analysis combining both ecological and farming system approaches. Changes in local livestock farming systems are regarded as the main drivers of landscape change [5], an assumption supported by increasing evidence of the role played by agricultural land use in landscape dynamics [7, 26, 29]. The ecological study involves field observations of grassland colonization by ash. The study of agricultural 
land-use dynamics is based on the collection of information on current and past land management practices by means of interviews with farmers.

\section{Methods}

The overall method is based on the assumption that a suitable interdisciplinary scheme must simultaneously preserve the possibility of disciplinary advances and transversal analysis $[5,17,18]$. Therefore, (1) a specific field research scheme was established for each discipline with reference to disciplinary issues, (2) the same geographical reference area was selected and a common Geographical Information System (GIS) (Arcview ${ }^{\circledR} 3.2$ [15]) was built, and (3) the transversal issues were identified from the joint analysis of the advances made in each discipline.

\subsection{Study site}

The selected common geographical area was the municipality of Villelongue $\left(00^{\circ} 03^{\prime} \mathrm{W}\right.$ and $\left.42^{\circ} 57^{\prime} \mathrm{N}\right)$, a village in the peripheral area of the Pyrenees National Park (Fig. 1). The average annual temperature is $12.5^{\circ} \mathrm{C}\left(6^{\circ} \mathrm{C}\right.$ for January and $20^{\circ} \mathrm{C}$ for August) and the average annual precipitation is $1000 \mathrm{~mm}(58.9 \mathrm{~mm}$ for July and $111.3 \mathrm{~mm}$ for April; data from Meteo France, years 1983-2001).
Villelongue has a total surface area of about 2,050 ha. Common lands and summer pastures represent more than 1,680 ha. Private agricultural lands, which cover about 300 ha, lie between 450 and 1300 m a.s.l. Often steeply sloped $(7 \%$ of the surface area has a gradient of more than $30 \%$ ), these lands are currently cultivated by eight farmers. In 1955, there were 52 farms in the village. Abandoned agricultural land without any connection to current farms covers about 100 ha $(30 \%$ of the previously privately cultivated land). The farmland is mainly dedicated to grassland for pasture and haymaking. The agricultural holdings are quite small (average of $18.2 \mathrm{ha}$ ) and feature extensive livestock farming systems: goat, cattle or mixed cattle and sheep farming (mainly for meat).

\subsection{Study scheme}

\subsubsection{Assessment of ash colonization}

The aim of the ecological approach is to assess the processes and stages of colonization of grasslands by ash on the village farmland. This approach is based on the assessment of the composition of vegetation on a selection of 98 ecological stations, which are representative of the array of grassland use (assessed from the physiognomy of the grassland vegetation in early summer). Three main categories of agricultural land use were considered: meadows (grasslands used for haymaking that can also be grazed), pastures
Fig. 1 Study site. Parcels investigated in the village of Villelongue, France

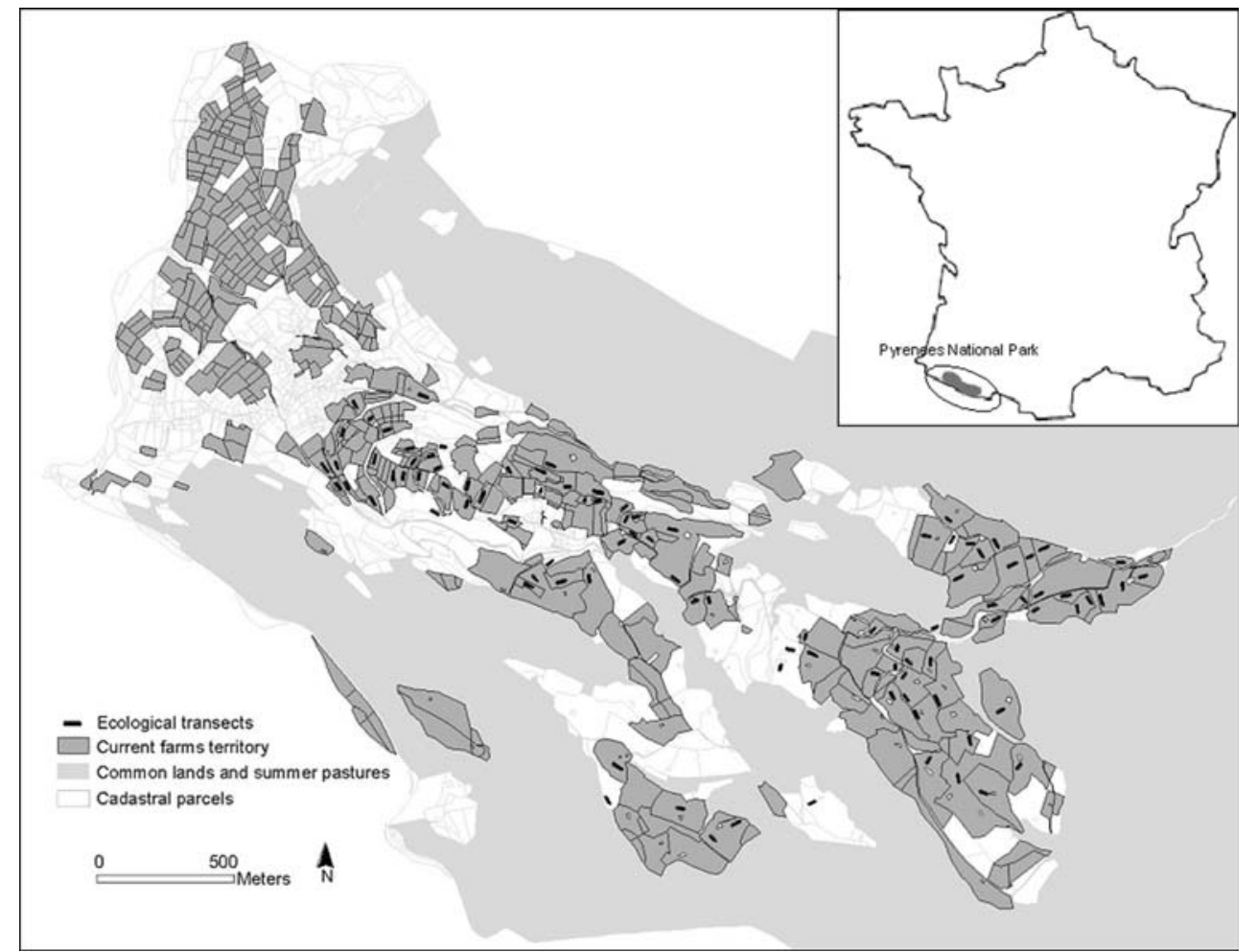


(grasslands that are grazed only) and abandoned grasslands (no longer used by the farmers).

The botanical composition of the 98 stations was recorded by using the point quadrat analysis method [13, 27]. The method consists of making 50 observations along a 20-m transect (i.e., one observation every $40 \mathrm{~cm}$ ). Edge effects and undesired environmental heterogeneity (e.g., rock outcrops, dung patches) were carefully avoided when localizing the transect in the station (Fig. 1). For each of the 50 points, the presence of a given plant species was noted when the species foliage was in contact with a steel needle stuck vertically into the ground. Species abundance was considered as the sum of all occurrences recorded along a transect (range of abundance: 0-50).

The utilization intensity of the grasslands that are cut and/or grazed was indirectly evaluated from their botanical composition by using the calibrated reference model established by Balent [3] in another Pyrenean valley with similar climatic and pedological conditions (Fig. 2). This model, built from a correspondence analysis (CA model), ordinates the grassland stations along two orthogonal axes which have been proven to reflect respectively their biomass production (BP) (CA F1 axis) and the amount of biomass removal (BR) due to both animal grazing and haymaking (CA F2 axis). The CA model axes were calibrated by using external data [3]. BP, estimated from

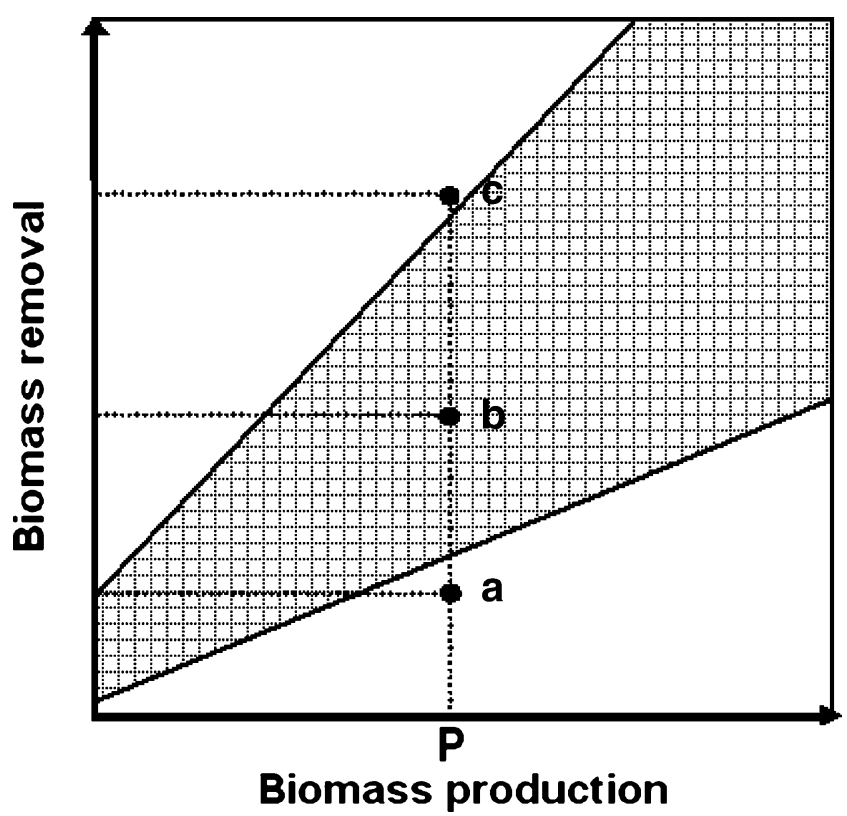

Fig. 2 Reference model for comparing the relationships between grassland biomass production (BP) and grassland biomass removal (BR) from grassland botanical composition (from Balent [3]). For a given level of BP (P), there is a range of possible levels of BR. (a) A low percentage of produced biomass is removed leading to biomass accumulation (underutilization). (b) An intermediate and widely observed situation. (c) All the produced biomass is removed leading to the development of bare soil patches (overutilization). Oblique lines correspond to constant values of the $\mathrm{BR} / \mathrm{BP}$ ratio
$\mathrm{N}, \mathrm{P}$ and $\mathrm{K}$ concentration in plants, is known to be correlated to annual dry matter production [14]. BR was estimated by pooling the results from direct measurement of grazing intake on the study territory and from survey data on hay meadow yields [3]. The intensity of use was approximated by means of the ratio between BR and BP, as shown in Fig. 2. Calibration, validation and confrontation with theory have confirmed the overall quality of this empirical model, established from plant communities in equilibrium with management [3].

The passive ordination of the 98 transects along axes 1 and 2 of the CA model was performed by using the mean of the CA transition formula:

$G_{1 j}=1 / \sqrt{\lambda_{1}} \sum_{1}^{n} f_{j}(i) \times F_{1}(i)$

where $G_{1 j}$ is the score of sample $j$ on the CA model's $F_{1}$ axis, $\lambda_{1}$ is the eigenvalue of the CA model's $F_{1}$ axis, $f_{j}(i)$ is the frequency of species $i$ in sample $j$, and $F_{1}(i)$ is the score of species $i$ on the CA model's $F_{1}$ axis. $G_{1 \mathrm{j}}$ is the weighted average of the scores of the species in the CA model's sample $j$. The CA model's $\lambda_{1}$ is equal to 0.442 , i.e., $F_{1}$ canonical correlation between species and samples $\left(\sqrt{\lambda_{1}}\right)=0.66$, and the CA model's $\lambda_{2}$ is equal to 0.242 , i.e., $F_{2}$ canonical correlation $=0.49$.

In our case study, 112 of the 208 species found on the 98 transects were common to the 217 species in the CA model. These 112 species represent $89.11 \%$ of the total abundance of the 208 species. The 105 species in the CA model that are not in our sample represent $9.49 \%$ of the total abundance of the 217 species in the CA model. The passive ordination of the 98 transects in the CA model can therefore be considered as representative of the ecological conditions of the transects.

\subsubsection{Assessment and change of agricultural land use}

The agricultural aspect of this study focused on the understanding of land-use change on the farmlands. Agricultural land use was assessed at the cadastral parcel scale, according to the three aforementioned categories. The agricultural system's approach was based on interviews with each of the farmers who are currently using land in the village (Fig. 1). A two-step interview method was developed from previous research [16]. The first step consisted of collecting general information about family farm characteristics, agricultural production systems, their respective changes since 1950 as well as compiling a comprehensive list of the farm parcels. The second step, based on a map of the farmland drawn up within the GIS, consisted of collecting data on current and past land tenure, type of land use and grassland management practices for each of the parcels. 


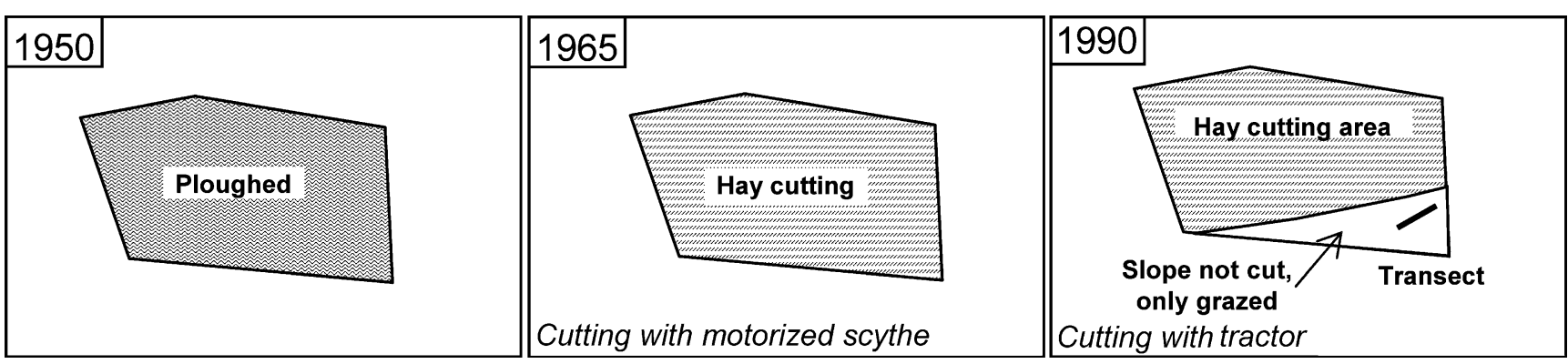

Fig. 3 Intra-parcel heterogeneity in land-use histories. Land-use history in the whole parcel is "cropland till 1965 and then meadows", but at the transect location there is a particular current land use (pasture) and a particular history: "cropland till 1965, then meadows till 1990 and then pasture"

\subsubsection{Specific development for the interdisciplinary work}

the consecutive land-use types from 1950 to 2003, and the dates of transitions from one land-use type to another. Land-use histories can be grouped according to four dynamics as defined by Mottet et al. [23]: stable (no change in land use over the period); extensification (one or two changes resulting in a loss of utilization intensity, e.g., Meadow $\rightarrow$ Pasture); intensification (one or two changes towards increased utilization intensity, e.g., Abandoned $\rightarrow$ Pasture); and re-intensification (extensification followed by a second change that consisted of an intensification, e.g., Meadow $\rightarrow$ Abandoned $\rightarrow$ Pasture).

Current grazing systems were assessed from the reconstruction with the farmer of the year-round calendar of grassland use (dates and duration, type and number of animals). The grazing pressure (GP) was calculated for each pasture according to the following formula:

$\mathrm{GP}=\frac{\sum_{i} N_{i} \times C U_{i} \times T_{i}}{S}$

where $N_{i}$ is the number of animals of type $i, C U_{i}$ is the value of the cattle unit for animals of type $i$ ( 1 cattle unit $=$ 1 cow $=6.5$ sheep), $T_{i}$ is the time spent by the animals of type $i$ on the parcels during the year and $S$ is the total surface area of the parcel in ha. GP is therefore calculated in equivalent grazing days for one cattle unit per ha. It represents the number of days spent by all livestock units on a parcel in 1 year, divided by the surface area of that parcel. GP is considered to be an agricultural indicator of land-use intensity. GP can vary between farms, and also within a farm on the parcel scale. The average GP of the pastures on the three farms that could be considered in the analysis differed significantly $\left(P=0.000 ; R^{2}=0.879\right.$; data for farms 4 and 5 being eliminated from the ANOVA, since the sample encompassed only one parcel on these farms). The parcels on farm 1 have highly variable GP values, whereas the parcels on farms 2 and 3 have a similar GP.
The stations and parcels do not correspond in landscape in the same level of organization as defined by Allen and Starr [1]. Stations concern the spatial variations in the composition of grassland vegetation. Land-use histories and management practices are usually studied at the parcel level, as the parcel is the basic land unit in the organization of land tenure and in land-use practices. The fact that some transects were represented in parcels that are not part of a current farm (eight transects) led the agricultural scientist to complete his inquiries by diversifying his sources of information (retired farmers). Conversely, in a few cases, two ecological transects were made in the same parcel. This led the agricultural scientist to look for data at the infraparcel level, in order to meet the interdisciplinary require-

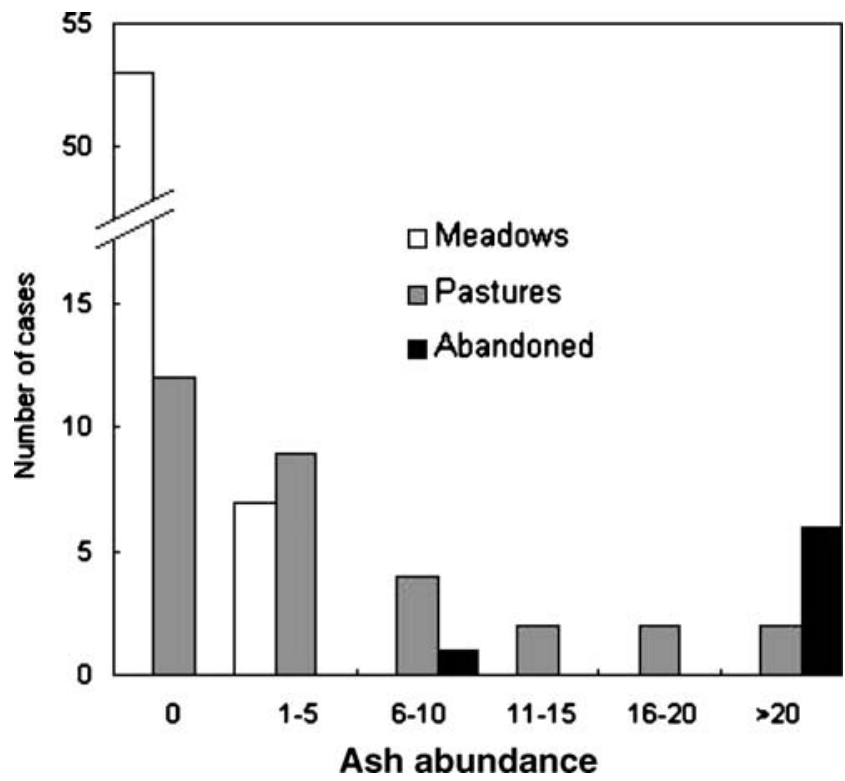

Fig. 4 Ash abundance according to current land use (assessment at the station level) 
Fig. 5 Variations in ash abundance in current meadows and pastures according to the method applied for assessment of the land use type (bars in dots correspond to the number of cases where land use is "pasture" at the station level, but "meadow" at the parcel level)

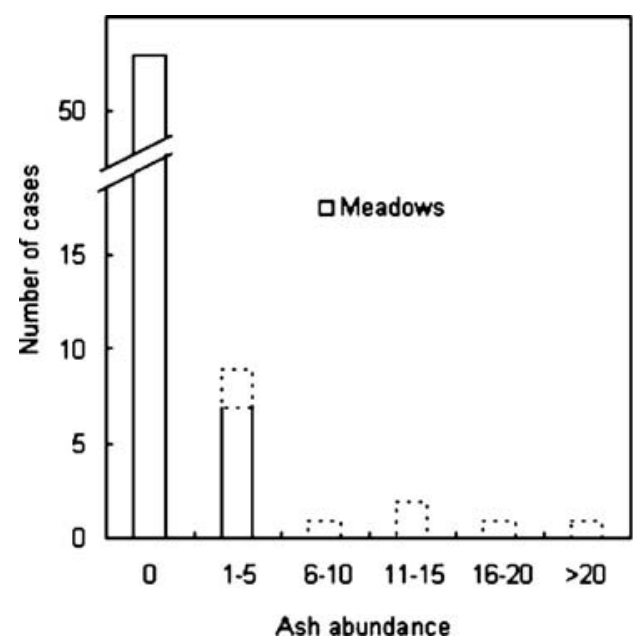

ments. Figure 3 shows an example of a parcel where particular additional data were needed. The work reported in the paper was carried out on 93 parcels, 5 of which contained 2 stations.

\subsection{Data processing and analysis methodology}

Analysis was carried out in three stages.

(1) We tried to understand the role of current land use in the ash colonization process. We started by using an ANOVA to compare ash abundance in meadows, pastures and on abandoned land. We analyzed the differences between results when assessing land use either at the parcel or station level. All the transects were ordinated in the CA model according to their botanical composition, in order to assess whether different land-use types present different BR/BP situations.

(2) For parcels that are grazed only (pastures), we investigated the relationships between land-use intensity and the level of ash colonization. Ash presence/absence was analyzed with reference to GP (Kolmogorov-Smirnov test). Since GP is a gross measurement of herbage off-take by grazing, it does not make it possible to account for the utilization intensity of the grass produced. We used GP as a basis for comparing grazing intensity with reference to the grassland production yield. In our first analysis, pastures were assimilated with the botanical stations and then ordinated in the ecological CA model, in order to assess the role of utilization intensity (BR/BP) in the ash colonization process. In our second analysis, we used the projection on the BP gradient and the calculated GP (Student's $t$-test).

(3) We attempted to understand the role of past land use. We determined the type of land-use history on each station, and for the pastures, we analyzed the relationship between presence/absence of ash and the types of land-use histories (Yates corrected $\chi^{2}$ ). We also compared current grazing intensities with reference to land-use histories by using an ANOVA.

All the tests were run with SYSTAT [28].
Fig. 6 Passive ordination of the 98 stations (a) and of stations with ash only (b) in the correspondence analysis model. The symbols refer to different land use types in (a) $(\times$ meadows, • pastures, $\star$ abandoned lands). The area between the two lines corresponds to the field of normal utilization. Overutilization and underutilization are found above the upper line and under the lower line, respectively
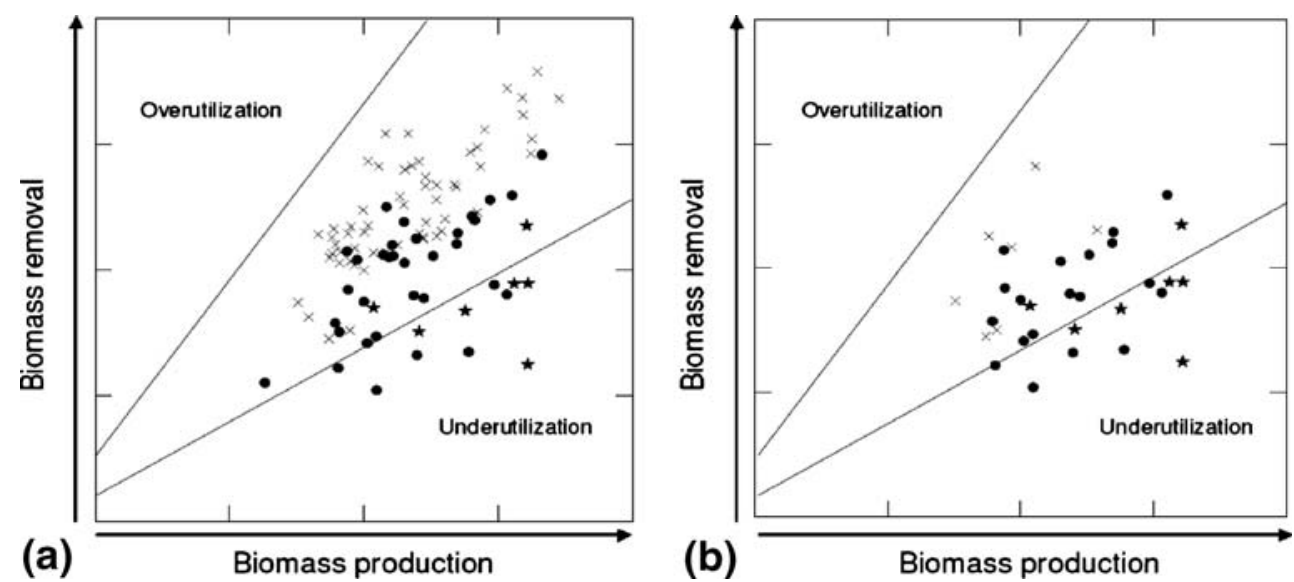


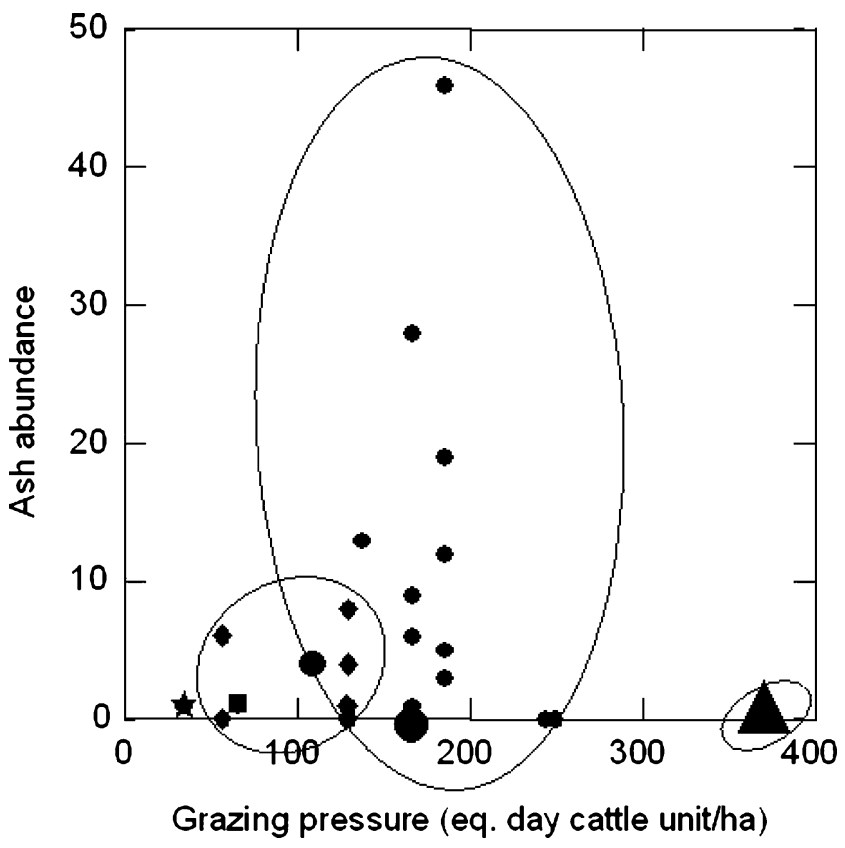

Fig. 7 Ash abundance with regard to grazing intensity. The symbols refer to five different farms. Data of farms $1(\bullet), 2(\bullet)$ and $3(\boldsymbol{\Delta})$ are graphically circled. Symbol size is proportional to the number of overlapping data items $(\boldsymbol{\Delta}=1$ transect, $\boldsymbol{\Delta}=5$ transects; $\boldsymbol{\Delta}>5$ transects)

\section{Results}

3.1 Current land use and ash colonization on all grassland types

Sixty parcels are currently used as meadows, 31 as pastures and 7 are abandoned. Ash is present on the three different land-use types. It is systematically present on the abandoned lands. Ash tree abundance differs significantly in relation to current land use $\left(R^{2}=0.716, P=0.000\right)$. In the meadow stations, ash presents low abundance levels (always less than 6 individuals), while it presents highly variable abundance levels in pasture stations (from 0 to more than 20 individuals). Ash abundance is at its highest in abandoned stations (from 6 to more than 20 individuals) (see Fig. 4).

Differences in the assessment of land-use intensity according to the ecological and the agricultural methods were found for seven of the stations. These are located in heterogeneous land-use parcels (pastured areas inside parcels of meadows). Figure 5 illustrates the differences in the ash abundance/current land-use relationship if land-use assessment is conducted at the parcel level.

The results of the passive ordination of all transects in the CA model (Fig. 6a) indicate that all the meadows and most of the pastures $(80 \%)$ are located in the normal grasslands utilization area, the BR level generally being higher in meadows than in pastures. Six pastures and all but one of the abandoned stations are located in the underutilization zone where the biomass accumulates due to undergrazing. The position of stations with ash in the model (Fig. 6b) indicates that stations colonized by ash usually have a low BR for a given BP. A large number of these stations are underused.

\subsection{Ash colonization in current pastures}

In parcels currently used as pastures, the presence of ash is significantly and negatively related to GP $(P=0.009)$. Ash appears to be absent where GP is high (GP $>200$ eq. day cattle unit/ha; Fig. 7). However, there is no relationship between GP and ash abundance at lower GP values. For any given GP value, ash abundance presents a broad variation range (from 3 to 46 individuals at 160 eq. day cattle unit/ha).

When grazing intensity was assessed from the passive ordination of the composition of pasture vegetation in the CA Model (Fig. 8a), a significant difference was found between parcels with ash and parcels without ash, pastures without ash having a higher BR rate than pastures with ash
Fig. 8 (a) Passive ordination of the 31 grazed stations in the correspondence analysis model. (b) Grazing pressure and biomass production (projection of the 31 grazed stations on the first gradient). Empty circles (o) are stations without ash and full circles $(\bullet)$ are stations with ash. Symbol size is proportional to ash abundance (range 1-46). Graphically squared stations represent high differences between (a) and (b), and graphically circled stations vary from biomass production

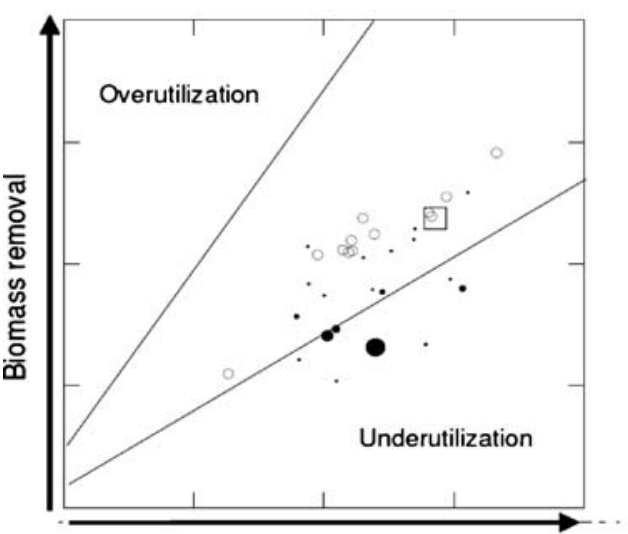

(a)

Biomass production

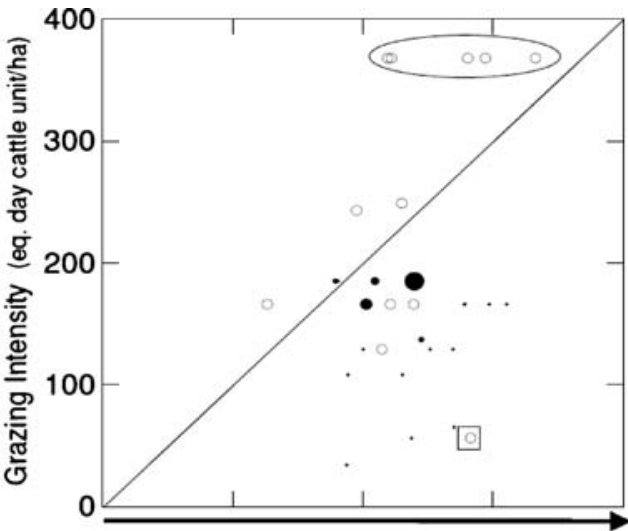

(b)

Biomass production 
Table 1 Ash presence/absence with regard to land-use histories assessed at the station level

\begin{tabular}{lll}
\hline Land-use histories and dynamics & Without ash & With ash \\
\hline Stable dynamic & & \\
Meadow since 1950 & 29 & 4 \\
Pasture since 1950 & 1 & - \\
Abandoned land since 1950 & - & 1 \\
Total & 30 & 5 \\
Extensification dynamics & & \\
Cropland $\rightarrow$ Meadow & 9 & 1 \\
Meadow $\rightarrow$ Pasture & 4 & 16 \\
Meadow $\rightarrow$ Abandoned & - & 4 \\
Pasture $\rightarrow$ Abandoned & - & 2 \\
Total & 13 & 23 \\
Re-intensification dynamic & & \\
Meadow $\rightarrow$ Pasture $\rightarrow$ Meadow & 12 & 2 \\
Meadow $\rightarrow$ Abandoned $\rightarrow$ Meadow & 3 & - \\
Meadow $\rightarrow$ Abandoned $\rightarrow$ Pasture & 7 & 2 \\
Total & 22 & 4 \\
Intensification dynamic & & 1 \\
Abandoned $\rightarrow$ Pasture & - & 33 \\
Total & 65 & \\
\hline
\end{tabular}

$(P=0.003)$. When grazing intensity was assessed by using the GP agricultural indicator, despite a similar general trend, considerable differences can be seen for some parcels (Fig. 8b).

In a particular case (squared in Fig. 8b), the GP appears to be very different from the BR estimate. We can also see a group of parcels with a very high GP (circled parcels) that does not exist in BR. The parcels in the group present large differences in their level of BP for the same GP. Additionally, some pastures with high ash abundance levels appear to have a lower GP than other pastures with lower ash abundance levels (Fig. 8b).

\subsection{Ash colonization and past land use}

The land-use histories identified on the 98 stations are presented in Table 1. The maximum number of changes during the period is two.

Among stations without ash, Stable meadow and Meadow $\rightarrow$ Pasture $\rightarrow$ Meadow are the most frequently represented histories. Stations with ash present more varied land-use histories. Among them, Meadow $\rightarrow$ Pasture is the most widely represented (16 out of 33 ).

With regard to pastures only, land-use histories for current pastures mainly correspond to Meadow $\rightarrow$ Pasture and Meadow $\rightarrow$ Abandoned $\rightarrow$ Pasture. There is a greater presence of ash in parcels with the first type of history than the other ones $(P=0.011)$. Current GP is significantly higher on parcels with the second type of history ( $\mu=292.3$ eq. day cattle unit; $P=0.000 ; R^{2}=0.498$; Stable pasture and Abandoned $\rightarrow$ Pasture were discarded from the ANOVA due to their low frequencies).

\section{Discussion and conclusion}

Our results confirm that agricultural practices are significant drivers of ash colonization in the study area, as already reported by Julien et al. [19]. Haymaking seems to prevent ash colonization totally, whereas ash is always present on abandoned lands. Important variations were found in the grazed grasslands, which we discuss in the next section 2 . Our work shows that the assessment of the real agricultural use of the parcels (haymaking, grazing or abandonment) helps us to understand the origin of the differences in the level of grassland colonization observed.

\subsection{Grazing intensity is a driver of ash colonization}

The ash colonization process seems to be more complex in the case of pastures than in other land-use types. Our results revealed that although ash is always absent where grazing intensity is high, ash abundance can vary significantly in relation to grazing intensity in other situations.

Pasture ordination in the CA model stressed the existence of a limit between pastures with and without ash that can correspond to a threshold in the utilization intensity (BR/BP ratio) [19]. Above this threshold, ash cannot become established. The relevance of this threshold evidenced by the ecological approach is confirmed by the grazing pressure estimates obtained in the agricultural science approach.

However, finer analysis revealed some inconsistencies between the assessments of land-use intensity according to the respective methods. The study of these inconsistencies helps us to appraise some particularities in the relationship between grazing and ash colonization. First, the gap observed in the grazing intensity assessment using the grazing pressure agricultural indicator does not exist when BR ecological estimate is used. The parcels isolated by this gap at one unique and very high grazing intensity all correspond to the same unit of grazing management (circled in Fig. 8b). However, we have shown, by using the ecological reference model, that they present different levels of BP. This result suggests that the grazing pressure is actually not the same on the different parcels in that unit.

With regard to the parcels squared on Fig. 8b, it appears to present a low grazing intensity on the basis of the GP calculation, whereas the BR appears high on the basis of 
the CA model. This suggested that a mistake had been made in the GP calculation, which was confirmed by a further interview with the tenant farmer - we learned that the parcel was also occasionally grazed by animals belonging to another farmer; a fact the farmer had omitted to mention in the initial interview.

Finally, we observed that parcels with high ash abundance levels had the highest GP, which seems illogical. We can explain this result by considering heterogeneities in the GP inside a parcel: some intra-parcel areas are actually grazed less than others and are therefore subject to a greater level of afforestation. Indeed, some transects were made on slopes where animals rarely go to graze. They prefer to stay on the flat area of the parcel where forage appetence is higher. Other transects were made in parcels where only one part is grazed in spring, the other being dedicated to haymaking and enclosed so that animals cannot enter during spring grazing. In autumn, the whole parcel is made available to animals, but we assumed that they may concentrate on the mowed area, which is flatter and has better forage quality. This was confirmed by Julien et al. [19], who demonstrated on the same field records that (1) vegetation was significantly more heterogeneous in pastures than in meadows and (2) spatially heterogeneous grassland was favorable to ash colonization. In such "patchy forage distribution" conditions, some studies have pointed out that grazing ungulates graze selectively [30, 31]. Therefore, the lower the grazing pressure, the greater the selection exercised in the grazing areas. Moreover, WallisDeVries et al. [30] have shown that selectivity is facilitated by large-scale heterogeneity: when the grazing area is large, animals choose large patches rather than small ones. In our case, where the grazing areas are large (several adjacent unfenced parcels) and the grazing pressure is moderate, cows can select the most attractive patches and reject the less attractive ones. This would explain that in our results, stations with the same GP within the low to moderate range of grazing intensity can present low or high ash abundance levels. The lessfavored areas in heterogeneous parcels are in fact subjected to biomass accumulation and therefore to greater colonization.

Finally, the assessment of grazing intensity appears as the key factor for understanding the colonization processes on grazed-only grasslands. Depending on the farmers' strategies, the average grazing pressure varies from one farm to another and the large array of grazing intensities observed within farms reflects the heterogeneous allocation of the herd among the pasture parcels. In the local-specific landscape conditions where all the grasslands are subjected to ash seed-rain, the variability in grazing management practices between and within farms must therefore be considered to be the source of the different ecological impacts of ash colonization in the landscape [6, 26].

\subsection{Role of past land use in the colonization process}

Ash can settle on parcels with very different land-use histories. Since we have demonstrated that current use alone explains ash non-colonization of meadows and colonization of abandoned land, we concentrated on pastures, where the pattern of colonization appears more complex. It could be imagined that converting a meadow directly into a pasture would prevent ash settlement and, on the contrary, that a period of abandonment before grazing would favor it. However, we observed the contrariness in our case study: meadows turned directly into pastures do have ash, whereas meadows abandoned and then re-grazed do not.

To understand this, we compared current grazing intensities on those parcels. It is significantly higher for pastures that had undergone a period of abandonment. They actually correspond to a re-intensification dynamic, whereas meadows directly turned into pastures are in an extensification dynamic, which indicates that a continued but extensive use of a parcel would not be sufficient to prevent ash colonization. Considering the dynamics of the parcel land use is therefore essential if we are to understand the potential development of the vegetation composition when trying to establish prospective studies.

\subsection{Interdisciplinary orientations}

The results of our study stress the importance of two main requirements for interdisciplinary research. (1) The detail of the study design must be jointly established between the different disciplines. Concentration of the research on the same geographical area does not appear sufficient to ensure the compatibility of the disciplinary data. For example, some parcels taken into account in the ecological work were not originally included in the agricultural system work, which concentrates on the study of the current farms' territory. Further evaluation of the specific needs of the respective disciplines before carrying out the fieldwork could have saved additional work, by making it possible to select, insofar as possible, ecological stations within the parcels of the current farms. (2) The interdisciplinary questions must be answered without altering the coherence of the disciplinary approaches. For example, we were faced with the classic problem of matching the respective scales of analysis between disciplines (station and parcel). We have demonstrated that our assessment of land use needs to be focused at the station level, due to grassland production and land-use heterogeneity inside the cadastre parcels. Intra-parcel heterogeneities are often neglected in agricul- 
tural works as the parcel is the relevant land unit. As Nagendra et al. [24] noted, matching the relevant ecological unit of analysis to the appropriate socio-politicoeconomic unit of analysis is a key parameter in interdisciplinary works. These particular demands led us to collect specific data during interviews, particularly on intra-parcel heterogeneities.

This raises the question of the agricultural calculation method for GP. This method is based on the technical management of the herd on the farm territory (allocation of the animals to the different parcels during the various grazing periods). GP must therefore be assessed at the parcel level; however, parcels are often grouped in larger management units, inside which animals are allowed to graze freely. The agricultural scientist calculates an average GP for the whole unit, whereas we have demonstrated that it is actually heterogeneous. Some developments of the method allow a finer assessment of BR removal by using direct observations of the animals during the grazing period (as used for establishing the CA model [3]).

The presence of intra-parcel heterogeneities also raises the question of the ecological assessment of ash abundance. The point quadrat method does not allow for the assessment of the exact number of individuals in the parcel. It only gives an estimation of the relative abundance of the species. It must therefore be used with care when trying to understand the colonization process at the landscape level.

To conclude, interdisciplinary work is generally helpful for each discipline. We have shown that intra-parcel management heterogeneities are at the origin of different ecological processes, which is worth taking into account in the ecological study of ash colonization processes. Moreover, the grazing intensity calculation allowed us to obtain realistic measurements in the field to complete and confirm the approach with a pre-established ecological model. The agricultural work also benefited from the study: the comparison of grazing intensity and BR led us to detect over- and under-evaluation of grazing intensity for some parcels.

Acknowledgments The study was funded by the Pyrenees National Park and the INRA (Grant 2002-45-S) for its ecological aspect, and by the European Union and the INRA as part of the European VisuLands program (Visualisation tools for public participation in the management of landscape change - QLRT-2001-01017) for its agricultural part. The authors would like to thank M. Degeilh, V. Haussard, C. Marcadet, V. Nadal, L. Raison and J. Willm for their contribution to field observations, S. Ladet for assistance with GIS data processing and M. Gonzalez for helpful comments.

\section{References}

1. Allen, T. F. H., \& Starr, T. B. (1982). Hierarchy: Perspective for Ecological Complexity. Chicago: University of Chicago Press.
2. Baldock, D., Beaufoy, G., Brouwer F., \& Godeschalk, F. (1996). Farming at the margins: Abandonment or redeployment of agricultural land in Europe. Institute for European Environmental Policy, London and Agricultural Economics Research Institute (LEI-DLO), The Hague.

3. Balent, G. (1991). Construction of a reference frame for studying the changes in species composition in grassland. Options Méditerranéennes, 15, 73-81.

4. Balent, G., \& Barrué-Pastor, M. (1986). Pratiques pastorales et stratégies foncières dans le processus de déprise de l'élevage montagnard en vallée d'Oô (Pyrénées Centrales), Revue géographique des Pyrénées et du Sud-Ouest, 57, 403-447.

5. Balent, G., \& Gibon, A. (1999). Organisation collective et individuelle dans la gestion des ressources pastorales: Conséquences sur la durabilité agro-écologique des ressources. Options Méditerranéennes, Série B, 27, 267-277.

6. Baudry, J., \& Thenail, C. (2004). Interactions between farming systems, riparian zones and landscape patterns: A case study in Western France. Landscape and Urban Planning, 70(1/2), 121-129.

7. Baudry, J., Alard, D., Thenail, C., Poudevigne, I., et al. (1996). The management of biodiversity in a cattle breeding area: The permanent grasslands in the Pays d'Auge (France). Acta Botanica Gallica, 143(4-5), 367-381.

8. Bazin, G. (1992). PAC et zones défavorisées: bilan et perspectives. Economie Rurale, 211, 40-46.

9. Cernusca, A., Bahn, M., Bayfield, N., Chemini, C. et al. (1998). ECOMONT: New concepts for assessing ecological effects of land use changes on terrestrial mountain ecosystems at an European scale. Verhandlungen der Gesellschaft für Ökologie, 28(3), 11.

10. Chassany, J. P. (1999). Processus de déprise agricole et enjeux socio-économiques. In Ingénieries Eau - Agriculture - Territoire (pp. 81-89). Antony: Cemagref Editions.

11. Chevalier, M. (1956). La vie humaine dans les Pyrénées ariégeoises. Tarascon sur Ariège: Résonance.

12. Curt, T., Brochiero, F., \& Prevosto, B. (1998). Boisement naturel des terres en déprise. Etat des lieux et analyse bibliographique. Travaux préparatoires à la définition d'un programme de recherche, lère partie (définition et typologie des boisements spontanés, analyse historique et géographique, 26 p.) et 2ème partie (état des connaissances sur les boisements spontanés: état de l'art bibliographique, 67 pp.), Gip ECOFOR/Cemagref.

13. Daget, P., \& Poissonet, J. (1971). Une méthode d'analyse phytologique des prairies. Critères d'application. Annales Agronomiques, (Paris) 22, 5-41.

14. Duru, M., Balent, G., \& Langlet, A. (1994). Mineral nutritional status and botanical composition of pastures. I. Effect on herbage accumulation. European Journal of Agronomy, 3, 43-51.

15. ESRI, Arc View ${ }^{\circledR}$ GIS. (1996). The geographical information system for everyone. Redlands, CA: Environmental Systems Research Institute, Inc.

16. Gibon, A. (1999). Etudier la diversité des exploitations agricoles pour appréhender les transformations locales de l'utilisation de l'espace: l'exemple d'une vallée du versant Nord des Pyrénées centrales. Options Méditerranéennes, Série B, 27, 197-215.

17. Gibon, A. (2000). Entretien des paysages et durabilité de l'élevage dans les Pyrénées centrales: inquiétudes et espoirs, Association française de pastoralisme, Pastum special issue (2000): Le pastoralisme en France à l'aube des années (pp. 33-41).

18. Gibon, A., \& Flamant, J. C. (1985). Intérêt d'approches interdisciplinaires pour le développement de l'élevage en milieu difficile: un exemple d'action de recherche-développement dans les Pyrénées Centrales. SPEOC/ITOVIC Editions (pp. 538-552).

19. Julien, M. P., Alard, D., \& Balent, G. (2005). Patterns of ash (Fraxinus excelsior L.) colonization in mountain grasslands: The 
importance of management practices. Plant Ecology, 183(1), 177189.

20. Mac, D., Donald, J. R., Crabtree, G., Wiegsinger, T., Dax, T., Stamou, P., et al. (2000). Agricultural abandonment in mountain areas of Europe: Environmental consequences and policy response. Journal of Environmental Management, 59, 47-69.

21. Meeus, J. H. A. (1993). The transformation of agricultural landscapes in Western Europe. The Science of The Total Environment, 129(1-2), 171-190.

22. Morel, M. (2004). Estimation des boisements de sols non forestiers en France à partir des données de l'enquête Teruti (1992-2002). Personal communication.

23. Mottet, A., Ladet, S., Coqué, N., \& Gibon, A. (2006). Agricultural land-use change and its drivers in mountain landscapes: A case study in the Pyrenees. Agriculture, Ecosystem \& Environment, 114, 296-310.

24. Nagendra, H., Munroe, D. K., \& Southworth, J. (2000). From pattern to process: Landscape fragmentation and the analysis of land use/land cover change. Agriculture, Ecosystem \& Environment, 101(2-3), 111-115.
25. Olsson, E. G. A., Austrheim, G., \& Grenne, S. N. (2000). Landscape change patterns in mountains, land use and environmental diversity, Mid-Norway 1960-1993. Landscape Ecology, 15(2), 155-170.

26. Poudevigne, I., \& Alard, D. (1997). Landscape and agricultural patterns in rural areas: A case study in the Brionne Basin, Normandy, France. Journal of Environmental Management, 50(4), 335-349.

27. Stampfli, A. (1991). Accurate determination of vegetation change in meadows by successive points quadrat analysis. Vegetatio, 96, 185-194.

28. SYSTAT ${ }^{\circledR} 9.0$ for Windows ${ }^{\circledR}$ Statistics I (1999). Chicago, IL, USA: SPSS.

29. Thenail, C., Morvan, N., Moonen, C., Le Coeur, D., et al. (1997). The role of farms in landscape evolution: A major driving factor of ecological dynamics. Ecologia Mediterranea, 23(1-2), 71-90.

30. WallisDeVries, M. F., Laca, E. A., \& Demment, M. W. (1999). The importance of scale of patchiness for selectivity in grazing herbivores. Oecologia, 121, 355-363.

31. Weber, G. E., Jeltsch, F., Van Rooyen, N., \& Milton, S. J. (1998). Simulated long-term vegetation response to grazing heterogeneity in semi-arid rangelands. Journal of Applied Ecology, 35, 687-699. 